\title{
AMPK activation protects astrocytes from hypoxia-induced cell death
}

\author{
LELI BARIALAI ${ }^{1-3}$, MAJA I. STRECKER ${ }^{1-3}$, ANNA-LUISA LUGER ${ }^{1-3}$, \\ MANUEL JÄGER ${ }^{4}$, INES BRUNS ${ }^{1-3}$, ALINA C.M. SITTIG ${ }^{1-3}$, IRIS C. MILDENBERGER ${ }^{1-3,5,6}$, \\ SONJA M. HELLER ${ }^{1-3}$, ALBERTO DELAIDELLI ${ }^{1-3}$, NADJA I. LORENZ ${ }^{1-3}$, MARTIN VOSS ${ }^{1-3}$, \\ MICHAEL W. RONELLENFITSCH ${ }^{1-3}$, JOACHIM P. STEINBACH ${ }^{1-3}$ and MICHAEL C. BURGER ${ }^{1-3}$
}

\begin{abstract}
${ }^{1}$ Dr. Senckenberg Institute of Neurooncology, University Hospital Frankfurt, Goethe University, D-60528 Frankfurt am Main;
${ }^{2}$ University Cancer Center Frankfurt (UCT), University Hospital Frankfurt, Goethe University; ${ }^{3}$ German Cancer

Consortium (DKTK), Partner Site Frankfurt/Mainz; ${ }^{4}$ Department of Dermatology, Venerology and Allergology,

University Hospital Frankfurt, Goethe University, D-60590 Frankfurt am Main; ${ }^{5}$ Department of Neurology,

Mannheim Medical Center, University of Heidelberg, D-68167 Mannheim; ${ }^{6}$ DKTK CCU Neuroimmunology and Brain Tumor Immunology, German Cancer Research Center, D-69120 Heidelberg, Germany
\end{abstract}

Received July 20, 2019; Accepted February 10, 2020

DOI: $10.3892 / \mathrm{ijmm} .2020 .4528$

\begin{abstract}
Adenosine monophosphate (AMP)-activated protein kinase (AMPK) is a major cellular energy sensor that is activated by an increase in the AMP/adenosine triphosphate (ATP) ratio. This causes the initiation of adaptive cellular programs, leading to the inhibition of anabolic pathways and increasing ATP synthesis. AMPK indirectly inhibits mammalian target of rapamycin (mTOR) complex 1 (mTORC1), a serine/threonine kinase and central regulator of cell growth and metabolism, which integrates various growth inhibitory signals, such as
\end{abstract}

Correspondence to: Dr Michael C. Burger, Dr. Senckenberg Institute of Neurooncology, University Hospital Frankfurt, Goethe University, Schleusenweg 2-16, D-60528 Frankfurt am Main, Germany

E-mail: michael.burger@kgu.de

Abbreviations: 2DG, 2-deoxy-d-glucose; $\alpha \mathrm{KG}, \alpha$-ketoglutarate; ACC, acetyl-CoA carboxylase; Akt, serine/threonine kinase Akt/protein kinase B; AMP, adenosine monophosphate; AMPK, 5'adenosine monophosphate-activated protein kinase; ATP, adenosine triphosphate; DMEM, Dulbecco modified Eagle's minimal essential medium; DMSO, dimethyl sulfoxide; EGFR, epidermal growth factor receptor; FACS, fluorescence-activated cell sorting; FCS, fetal calf serum; GB, glioblastoma; LDH, lactate dehydrogenase; mTOR, mammalian target of rapamycin; mTORC1, mTOR complex 1; n.s., not significant; p-p42/44 MAPK, phospho-p42/44 mitogen-activated protein kinase; p-p90RSK, phospho-p90RSK (MAPK-activated protein kinase-1); PI, propidium iodide; PI3K, phosphoinositide 3-kinase; Rab11, Ras-related protein Rab-11; RPS6, ribosomal protein S6

Key words: neural cells, astrocytes, AMPK, mTOR, hypoxia, ischemia, neuroprotection the depletion of glucose, amino acids, ATP and oxygen. While neuroprotective approaches by definition focus on neurons, that are more sensitive under cell stress conditions, astrocytes play an important role in the cerebral energy homeostasis during ischemia. Therefore, the protection of astrocytic cells or other glial cells may contribute to the preservation of neuronal integrity and function. In the present study, it was thus hypothesized that a preventive induction of energy deprivation-activated signaling pathways via AMPK may protect astrocytes from hypoxia and glucose deprivation. Hypoxia-induced cell death was measured in a paradigm of hypoxia and partial glucose deprivation in vitro in the immortalized human astrocytic cell line SVG. Both the glycolysis inhibitor 2-deoxy-d-glucose (2DG) and the AMPK activator A-769662 induced the phosphorylation of AMPK, resulting in mTORC1 inhibition, as evidenced by a decrease in the phosphorylation of the target ribosomal protein S6 (RPS6). Treatment with both 2DG and A-769662 also decreased glucose consumption and lactate production. Furthermore, A-769662, but not 2DG induced an increase in oxygen consumption, possibly indicating a more efficient glucose utilization through oxidative phosphorylation. Hypoxia-induced cell death was profoundly reduced by treatment with $2 \mathrm{DG}$ or A-769662. On the whole, the findings of the present study demonstrate, that AMPK activation via 2DG or A-769662 protects astrocytes under hypoxic and glucose-depleted conditions.

\section{Introduction}

Adenosine monophosphate (AMP)-activated protein kinase (AMPK) is a major cellular energy sensor, which is activated by an intracellular increase in the AMP/adenosine triphosphate (ATP) ratio. AMPK activation induces the initiation of adaptive cellular programs, decreasing ATP consumption by inhibition of anabolic pathways and increasing ATP production. Subsequently, AMPK indirectly inhibits the mammalian target of rapamycin (mTOR) complex 1 (mTORC1) (1), which 
integrates signals from growth factor receptors and nutrient sensors, such as AMPK to adjust cell growth and metabolism. mTORC1 is activated by growth factor signals conveyed by receptor tyrosine kinases, such as epidermal growth factor receptor (EGFR) (2). Conversely, mTORC1 receives inhibitory signals when glucose, amino acids, ATP or oxygen are depleted under starvation conditions. mTORC1 adjusts cellular energy consumption to the available energy supply via the regulation of highly energy-intensive anabolic cellular processes, such as cap-dependent translation and cellular proliferation (3). A direct AMPK target protein also highly relevant for cellular energy consumption is the enzyme acetyl-CoA carboxylase (ACC), which is deactivated via phosphorylation (1). The inhibition of ACC activity, as a result of AMPK activation, results in a decrease in fatty acid synthesis (4). In summary, AMPK activation inhibits energy-consuming anabolic pathways and activates ATP-generating catabolic pathways through various targets, including the inhibition of mTOR and ACC activation, thereby stabilizing cellular energy homeostasis.

AMPK activity can be stimulated pharmacologically by direct activators, as well as indirectly by an increase in the concentration of AMP. A-769662 is a direct activator of AMPK (5). In glioblastoma (GB) cells, A-769662 has been shown to decrease glucose consumption and lactate production (6), and to protect GB cells from hypoxia-induced cell death, as well as from glucose deprivation (Lorenz et al, unpublished data). However, results obtained from neoplastic cells cannot easily be transferred into non-neoplastic astrocytic cells, as GB cells need to adapt to specific metabolic challenges in the tumor microenvironment and commonly rely on aerobic glycolysis for energy homeostasis (7). This phenotype has not been described for non-tumor glial cells.

The competitive glycolysis inhibitor, 2-deoxy-d-glucose (2DG), causes a decrease in ATP levels inducing phosphorylation of AMPK and hence its indirect activation. 2DG differs from glucose in having a hydrogen instead of a 2 'hydroxyl residue. Due to this structural similarity, 2DG is phosphorylated by hexokinase and then competitively binds to the glycolytic enzymes, hexokinase and phosphohexose isomerase. As a consequence, both aerobic and anaerobic glycolysis are blocked by $2 \mathrm{DG}(8,9)$.

Glutamine is metabolized as an alternative to glucose by conversion to glutamate and $\alpha$-ketoglutarate $(\alpha \mathrm{KG})$. Under aerobic conditions, $\alpha \mathrm{KG}$ is used in the Krebs cycle to produce ATP. The metabolization of glutamine to replenish ATP levels is known as 'glutaminolysis' (10). Furthermore, $\alpha$ KG produced from glutamine is used to replace biosynthetic intermediates from the Krebs cycle needed for the production of macromolecules, such as fatty acids and nucleic acids. The replacement of these biosynthetic intermediates (anaplerosis) permits its continued function and takes place both under aerobic and anaerobic conditions $(11,12)$.

Neuroprotection by definition seeks to preserve neuronal structure and function. However, non-neuronal cells, such as astrocytes play an important neuroprotective role in the pathophysiology leading to the cell death of neurons during ischemia (13). The overall goal of the present study was to evaluate the effects of AMPK activation on energy preservation and cell protection in astrocytes. This approach may indirectly be applied for neuroprotective purposes. Such an intervention could potentially be employed under several conditions: i) In the case of a cerebral ischemia, the periphery of the ischemic lesion (penumbra) is typically still supplied with some blood flow by collateral arteries. However, this blood flow is not sufficient to maintain neurologic function or even preserve the tissue affected from ischemic destruction longer than a short time interval of a few hours $(14,15)$; ii) furthermore, in patients where a vascular intervention in the carotid arteries or the aortic arch is planned, pre-conditioning the tissue at risk for a temporal interruption of the blood circulation through AMPK activation or mTOR inhibition may be feasible. Similarly, hypothermic perfusion is used as a feasible and effective neuroprotective approach during these interventions $(16,17)$.

The role of astrocytes in ischemia and in neuroprotection has recently received increasing attention (13), as it has become increasingly evident that astrocytes play central roles in the energy homeostasis of the brain, controlling cerebral blood flow $(18,19)$, the transport of extracellular water $(20)$, as well as the uptake, synthesis and secretion of neurotransmitters (21). Previous studies have focused on neuronal protection, while the role of astrocytes has been neglected, at least to the best of our knowledge. For example, Xie et al demonstrated that AMPK activation with A-769662 and silibinin protected murine cortical neurons and SH-SY5Y neuroblastoma cells from oxygen-glucose deprivation and re-oxygenation (22). The effect of AMPK activation by A-769662 was thus investigated in astrocytic cells under starvation conditions. As an established model for astrocytic cells, the SV40-immortalized astrocytic cell line, SVG, was used $(23,24)$. In the present study, the effects of direct AMPK activation via A-769662 and glycolysis inhibition via 2DG were investigated in SVG cells in an established paradigm of hypoxia-induced cell death.

It was hypothesized that a preventive induction of energy deprivation-activated signaling pathways via AMPK will protect astrocytes from permanent hypoxia and glucose deprivation.

\section{Materials and methods}

Cells and cell culture. SV40-immortalized astrocytic SVG cells were purchased from the American Type Culture Collection (ATCC; cat. no. CRL-8621). SVG cells were maintained in a cell culture incubator (Binder) at $37^{\circ} \mathrm{C}$ under a $5 \% \mathrm{CO}_{2}$ atmosphere. SVG cells were cultivated in Dulbecco modified Eagle's minimal essential medium (DMEM; Life Technologies; Thermo Fisher Scientific, Inc.) containing $10 \%$ fetal calf serum (FCS; Biochrom KG) supplemented with $100 \mathrm{IU} / \mathrm{ml}$ penicillin and $100 \mu \mathrm{g} / \mathrm{ml}$ streptomycin (Life Technologies; Thermo Fisher Scientific, Inc.). For the experimental conditions, DMEM glucose-free medium (Life Technologies; Thermo Fisher Scientific, Inc.) without FCS was supplemented with glucose to obtain the appropriate concentration. 2DG (Sigma-Aldrich; Merck KGaA) was used at a concentration of $10 \mathrm{mM}$ and A-769662 (R\&D Systems, Inc.) at a concentration of $100 \mu \mathrm{M}$. As the medium containing 2DG and A-769662 was left on the cells, these were treated until the read-out of the respective experiments (for details please see figure legends). Staurosporin (Sigma-Aldrich; Merck $\mathrm{KGaA}$ ) was used as a positive control for poly(ADP-ribose) 
polymerase (PARP) and caspase-3 cleavage and the induction of apoptotic cell death at a concentration of $1 \mu \mathrm{g} / \mathrm{ml}$. The duration of treatment with staurosporin was $12 \mathrm{~h}$.

SVG cells were seeded and allowed to attach in DMEM containing $10 \%$ FCS overnight under normoxic conditions ( $21 \%$ oxygen). Thereafter, the medium was, prior to incubating the cells under hypoxic conditions, replaced with serum-free DMEM containing the respective glucose concentrations supplemented with 2DG, A-769662 or the vehicle, dimethyl sulfoxide (DMSO). Hypoxia of $0.1 \%$ oxygen was induced by incubation in BD GasPak pouches (BD Biosciences) (25).

Cell viability assays. Cell viability was analyzed by propidium iodide (PI) staining and lactate dehydrogenase (LDH) release assay. For PI staining, 120,000 cells were seeded in a 24-well plate, and for LDH assay, 20,000 SVG cells per well were seeded in a 96-well plate. Cells were examined under a light microscope (Wilovert A, Helmut Hund $\mathrm{GmbH}$ ) following

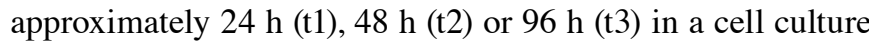
incubator (Binder) at $37^{\circ} \mathrm{C}$ under a $5 \% \mathrm{CO}_{2}$ atmosphere. The exact time points of measurements were fine-tuned to the respective extent of cell death. $\mathrm{LDH}$ activity was determined in the supernatant and after cell lysis. The ratio of LDH activity in the supernatant and after cell lysis was calculated as a surrogate marker of cell death as published earlier (26). $\mathrm{LDH}$ release assays were only performed at the time points of 24 and $48 \mathrm{~h}$ of incubation, as the results of the LDH measurements at the time point of $96 \mathrm{~h}$ with the glucose concentration of $25 \mathrm{mM}$ were unreliable due to high background enzyme activity. PI uptake was analyzed by flow cytometry using a BD Canto II flow cytometer and BD FACS Diva software version 6.1.3 (BD Biosciences), as previously described (26).

Western blot analysis. For western blot analysis, $3.4 \times 10^{6} \mathrm{SVG}$ cells were seeded in $10-\mathrm{cm}$ plastic dishes, allowed to attach overnight and then treated for $1 \mathrm{~h}$ with the vehicle, DMSO, 2DG, A-769662, or staurosporin as indicated in the respective figure legends. After washing with ice-cold PBS, the cells were scraped off the dish with a cell scraper and lysed with lysis buffer comprising $50 \mathrm{mM}$ Tris- $\mathrm{HCl}, 130 \mathrm{mM} \mathrm{NaCl}$, $5 \mathrm{mM}$ EDTA, $0.5 \%$ Nonidet P-40 and supplemented with $1 \%$ Halt ${ }^{\circledR}$ Protease and Phosphatase Inhibitor (Thermo Fisher Scientific, Inc.). Protein was quantified with the Bradford protein assay and aliquoted so that each lane contained $10 \mu \mathrm{g}$ for the PARP/caspase-3 western blot or $20 \mu \mathrm{g}$ for all other western blots. The lysates were diluted in Laemmli buffer and subjected to sodium dodecyl sulfate $12 \%$ polyacrylamide gel electrophoresis. After blotting with 5\% skim milk in TBST for $1 \mathrm{~h}$ at room temperature, the blotting membranes (nitrocellulose blotting membrane $0.45 \mu \mathrm{m}$, cat. no. 10600016; GE Healthcare Life Sciences) were incubated for $12 \mathrm{~h}$ at $7^{\circ} \mathrm{C}$ with antibodies diluted as indicated: Rabbit anti-PARP (cat. no. 9542), rabbit anti-cleaved caspase-3 Asp175 (cat. no. 9664), rabbit anti-p-ACC Ser79 (cat. no. 3661), rabbit anti-phospho-AMPK $\alpha$ Thr172 (cat. no. 2531), rabbit Pathscan Multiplex Western Cocktail I (cat. no. 5301; containing antibodies against p-p90RSK, p-Akt, p-p42/44, MAPK, p-RPS6 and Rab11) (all diluted 1:1,000; all from Cell Signaling Technology) or goat anti-actin (cat. no. sc-1616, diluted 1:2,000; Santa Cruz Biotechnology, Inc.). Secondary goat anti-rabbit antibody and donkey anti-goat antibodies were used respectively (diluted 1:5,000, cat. no. sc-2004 and cat. no. sc-2020; Santa Cruz Biotechnology, Inc.). The secondary antibodies were incubated for $1 \mathrm{~h}$ at room temperature $\left(21^{\circ} \mathrm{C}\right)$. For detection, a chemiluminescence solution composed of $1 \mathrm{ml}$ solution A $(50 \mathrm{mg}$ luminol in $200 \mathrm{ml} 0.1 \mathrm{M}$ Tris- $\mathrm{HCl}, \mathrm{pH} 8.6), 100 \mu 1$ solution $\mathrm{B}$ (11 mg p-hydroxy-coumaric acid in $10 \mathrm{ml}$ DMSO) and $0.3 \mu \mathrm{l}$ $\mathrm{H}_{2} \mathrm{O}_{2}(30 \%)$ was added. The quantification of the western blot bands was performed by measuring the pixel density of the scanned films using ImageJ 1.51f software (NIH). All western blot analyses were performed at least 3 times, and a representative blot was selected for presentation and quantification.

Measurement of glucose, lactate and ATP concentrations. Glucose and lactate concentrations were measured in cell-free supernatants with a biochemistry analyzer Hitachy 917 (Roche). For the analysis of oxygen consumption, cultured cells were overlaid with paraffin oil and oxygen concentrations were measured every 15 min utilizing a fluorescence-based assay with a sensor at the bottom of each well (OxoDish, PreSens), as previously described (27).

For ATP assays, plates (96-well plates with 20,000 SVG cells per well) were placed on ice immediately following incubation at $37^{\circ} \mathrm{C}$ under normoxic or hypoxic $\left(0.1 \% \mathrm{O}_{2}\right)$ conditions for $6 \mathrm{~h}$. The SVG cells were pelleted by centrifugation and lysed with ATP releasing agent (Sigma-Aldrich; Merck KGaA). The ATP concentration was then measured with a luciferase-based CLS II kit (Boehringer), as previously described (25).

Statistical analysis. Data are presented as the mean values in the figures, \pm the standard deviation, which were calculated with Excel version 2010 (Microsoft, Inc.). Glucose and lactate concentrations were measured from pooled supernatant of 5 wells. For western blot analysis quantifications, the intensities of an exemplary blot were normalized to actin expression. For all other experiments, statistical analyses were performed with GraphPad Prism 7 (GraphPad Software, Inc.). Values of $\mathrm{P} \geq 0.05, \mathrm{P}<0.05, \mathrm{P}<0.01$ and $\mathrm{P}<0.001$ were regarded as not significant (n.s.), significant, highly significant and extremely significant, respectively. For oxygen consumption analyses, a non-linear regression analysis followed by ANOVA and the Tukey's multiple comparison test was used. For all other statistical calculations, ANOVA and Dunnett's multiple comparison test was used.

\section{Results}

Inhibition of glycolysis and activation of AMPK protects SVG cells from hypoxia-induced cell death in the absence of glutamine. Glucose and oxygen concentrations are two decisive determinants in cerebral ischemic lesions. Therefore, the present study first employed an established paradigm (26-28) of severe hypoxia with $0.1 \%$ oxygen, varied glucose concentrations and complete glutamine deprivation. Cell death was measured by flow cytometry [fluorescence-activated cell sorting (FACS)] as a percentage of PI-positive cells (for exemplary PI FACS plots please see Fig. S1). A partial glucose restriction with a glucose concentration of $2 \mathrm{mM}$, a roughly normoglycemic concentration of $5 \mathrm{mM}$, as well as a highly supraphysiological glucose concentration of $25 \mathrm{mM}$ were 
tested. Both glycolysis inhibition with 2DG and direct AMPK activation with A-769662 protected the SVG cells from hypoxia-induced cell death (Fig. 1A, C and E). This effect was most pronounced at glucose concentrations of 2 and $5 \mathrm{mM}$, although it was still detectable at the supraphysiological high glucose concentration of $25 \mathrm{mM}$. The earlier time points were selected for the experiments with lower glucose concentrations to adjust for the earlier induction of cell death under these lower glucose concentrations. 2DG had a toxic effect at a glucose concentration of $5 \mathrm{mM}$, but not at 2 or $25 \mathrm{mM}$ (Fig. 1B, D and F). A-769662 protected the SVG cells from glutamine deprivation at glucose concentrations of 5 and $25 \mathrm{mM}$ under normoxic conditions (Fig. 1B, D and F).

The protective effects of 2DG and A-769662 under hypoxic conditions were also confirmed by light microscopic imaging. Cells treated with the vehicle, DMSO, detached more rapidly and commonly displayed condensation and pyknosis under hypoxic conditions, as compared to the cells treated with 2DG and A-769662 (Fig. 1, photo inlays). Western blot analysis detected an increased caspase-3 and PARP cleavage (cCaspase 3 and cPARP) in the SVG cells treated with the vehicle (DMSO) as compared to the cells treated with $2 \mathrm{DG}$ or A-769662, indicating an apoptotic cell death mechanism (Fig. S2).

Inhibition of glycolysis and activation of AMPK protects SVG cells from hypoxia-induced cell death in the presence of glutamine. To examine the possibility that glutamine may be metabolized to replenish ATP levels and to thus protect the cells from glucose deprivation, the experiments described above were repeated in the presence of glutamine. Comparable to the results obtained with glutamine withdrawal, 2DG and A-769662 protected the SVG cells from hypoxia (Fig. S3A and C) at glucose concentrations of 2 and $5 \mathrm{mM}$, and glutamine concentrations of $4 \mathrm{mM}$. Under the supraphysiologically high glucose concentration of $25 \mathrm{mM}$ and a glutamine concentration of $4 \mathrm{mM}, 2 \mathrm{DG}$ did not protect the SVG cells from hypoxia; however, A-769662 still had a protective effect (Fig. S3E). Under normoxic conditions and glucose concentrations of $5 \mathrm{mM}, 2 \mathrm{DG}$ and A-769662 exerted a toxic effect, while at a glucose concentration of $25 \mathrm{mM}$, only A-769662 was toxic (Fig. S3B, D and F). In summary, glutamine was unable to compensate for the withdrawal of glucose under these conditions.

Effect of 2DG and A-769662 on cell viability under hypoxic conditions. The results obtained by PI staining were confirmed by $\mathrm{LDH}$ release assays. The protective effect of $2 \mathrm{DG}$ and A-769662 was verified under hypoxic conditions supplemented with 2 and $5 \mathrm{mM}$ glucose without the addition of glutamine, as evidenced by a reduced cellular LDH release (Fig. S4).

Effect of 2DG and A-769662 on AMPK and the target enzyme $A C C$. To examine the effect of A-769662 and 2DG on metabolic pathways critical for fatty acid biosynthesis in astrocytes, western blot analysis was performed for p-ACC (Ser79), as a readout of its enzymatic activity. Fatty acid biosynthesis is highly energy-intensive and, alongside protein biosynthesis, consumes a large portion of the ATP produced by the cell. Treatment of the SVG cells with 2DG resulted in ACC phosphorylation and therefore, in deactivation under normoxic and hypoxic conditions with glucose concentrations of 2 and $5 \mathrm{mM}$ (Fig. 2A and B, and quantification of intensities in $\mathrm{D}$ and $\mathrm{E}$ ). At $25 \mathrm{mM}$ glucose, 2DG increased ACC phosphorylation only under hypoxic, but not under normoxic conditions (Fig. 2C, and quantification of intensities in F). 2DG increased the phosphorylation and therefore, the activation of AMPK both under normoxic and hypoxic conditions at glucose concentrations of 2 and $5 \mathrm{mM}$ (Fig. 2A and B, and quantification of intensities in $\mathrm{G}$ and $\mathrm{H}$ ). In medium supplemented with $25 \mathrm{mM}$ glucose, there was a slight increase in AMPK phosphorylation under normoxic, but not under hypoxic conditions (Fig. 2C, and quantification of intensities in I).

Effect of 2DG and A-769662 on Akt and ribosomal protein S6 (RPS6, mTORC1 downstream target). To examine the effect of 2DG and A-769662 on mTORC1 signaling, western blot analysis for key components of this pathway was performed. Treatment of the SVG cells with 2DG did not alter the phosphorylation of serine/threonine kinase Akt/protein kinase B (Akt) and the mTORC1 downstream target, ribosomal protein S6 (p-RPS6), under normoxic and hypoxic conditions at glucose concentrations of 2, 5 and $25 \mathrm{mM}$ (Fig. 3A-C). The exposure of the SVG cells to A-769662 decreased the phosphorylation of RPS6 under normoxic and hypoxic conditions at glucose concentrations of 5 and $25 \mathrm{mM}$ (Fig. 3B and C, and quantification of intensities in $\mathrm{E}$ and $\mathrm{F}$ ). At the low glucose concentration of $2 \mathrm{mM}$, RPS6 phosphorylation was decreased by A-769662 only in normoxic, but not hypoxic conditions (Fig. 3A, and quantification of intensities in D). Overall, these results indicate an inactivation of $\mathrm{mTORC} 1$ in response to 2DG and A-769662 through AMPK activation. Similarly, the phosphorylation of Akt was reduced by A-769662 treatment under normoxic and hypoxic conditions at glucose concentrations of 2, 5 and $25 \mathrm{mM}$ (Fig. 3A-C). As expected, no relevant changes in the levels of pospho-p90RSK (p-p90RSK) and p-p42/44 MAPK, which are not regulated by mTORC1, were observed.

Glucose concentration of SVG cells treated with $2 D G$ and $A-769662$. The extracellular glucose concentration in the cell culture medium was measured in the absence of glutamine to examine the effects of 2DG and A-769662 on glucose consumption in astrocytes under hypoxic conditions. Glucose concentrations in the cell culture medium were measured after 24,48 and $72 \mathrm{~h}$. The results following treatment with 2DG and A-769662 were compared to treatment with the vehicle, DMSO, at the respective time points. A higher glucose concentration in the medium following treatment with 2DG or A-769662 as compared to treatment with the vehicle, DMSO, at the same time point is equivalent to a decrease in glucose consumption by 2DG or A-769662 treatment, respectively. Treatment of the SVG cells with 2DG led to reduced glucose consumption under normoxic and hypoxic conditions at glucose concentrations of 2 and $5 \mathrm{mM}$ (Fig. 4A-D). Under the supraphysiologically high glucose concentration of $25 \mathrm{mM}$, no effect of 2DG treatment on glucose consumption was observed (Fig. 4E and F). Treatment with A-769662 led to reduced glucose consumption under normoxic and hypoxic conditions under all glucose concentrations examined (2, 5 and $25 \mathrm{mM}$; Fig. 4). 

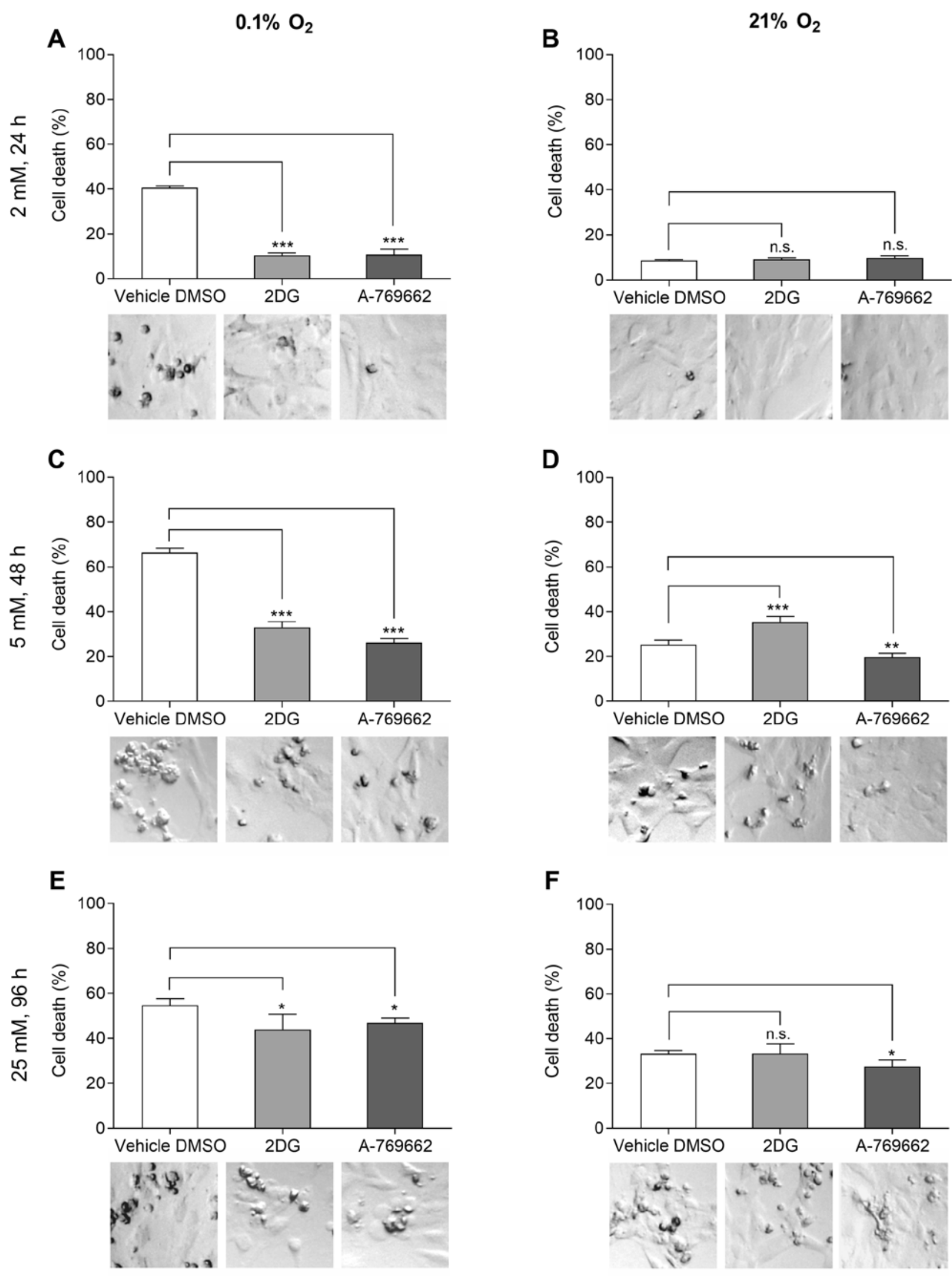

Figure 1. Inhibition of glycolysis and activation of AMPK protects SVG cells from hypoxia-induced cell death in the absence of glutamine. Effects of 2DG and A-769662 on cell viability under hypoxic $\left(0.1 \% \mathrm{O}_{2}\right)$ and normoxic $\left(21 \% \mathrm{O}_{2}\right)$ conditions were measured with PI-FACS. SVG cells were exposed to serum-free DMEM with 2, 5 or $25 \mathrm{mM}$ glucose, vehicle DMSO, 2DG or A-769662 and hypoxia or normoxia. PI-positive cells are presented as percentage of the total cell count. Exposure to $2 \mathrm{mM}$ glucose and (A) hypoxia or (B) normoxia, $24 \mathrm{~h}$ treatment. Exposure to $5 \mathrm{mM}$ glucose and (C) hypoxia or (D) normoxia, $48 \mathrm{~h}$ treatment. Exposure to $25 \mathrm{mM}$ glucose and (E) hypoxia or (F) normoxia, 96 h treatment $\left[\mathrm{n}=4\right.$; n.s., not significant $(\mathrm{P} \geq 0.05) ;{ }^{*} \mathrm{P}<0.05,{ }^{* * *} \mathrm{P}<0.01,{ }^{* * * *} \mathrm{P}<0.001$, ANOVA with Dunnett's multiple comparisons test]. Light microscopic images (original magnification, $\mathrm{x} 40$; scale bar, $25 \mu \mathrm{m}$ ) of the SVG cells are presented in the photo inlays. 2DG, 2-deoxy-d-glucose. 
$2 \mathrm{mM}$ glucose

A

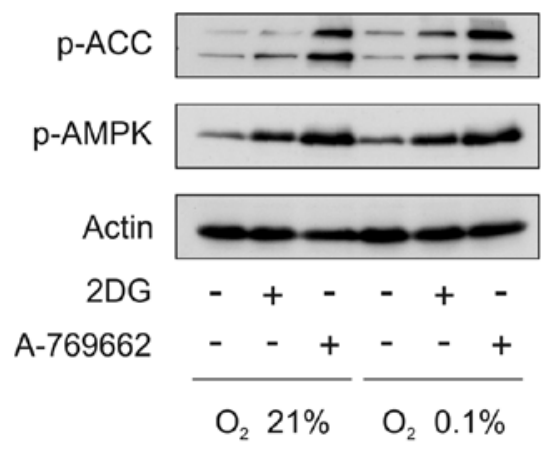

$5 \mathrm{mM}$ glucose

B

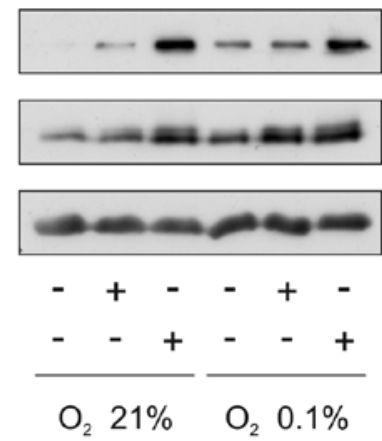

E

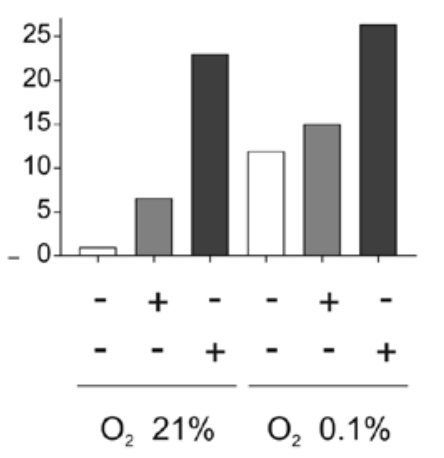

H

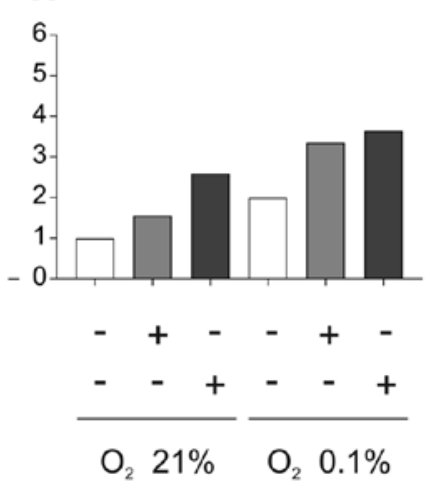

$25 \mathrm{mM}$ glucose

C

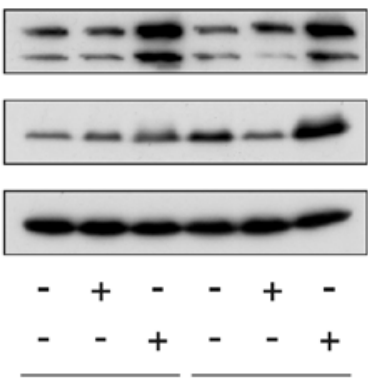

$\mathrm{O}_{2} 21 \% \quad \mathrm{O}_{2} \quad 0.1 \%$

$\mathbf{F}$

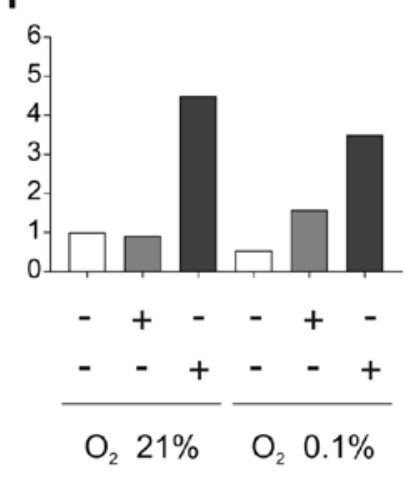

I

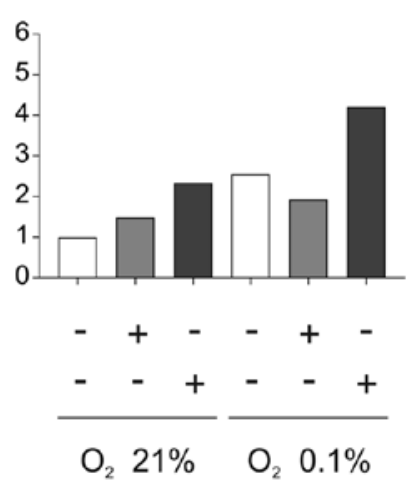

Figure 2. Effect of 2DG and A-769662 on AMPK and the target enzyme, ACC. SVG cells were exposed to serum-free DMEM with glucose concentrations of (A, D and G) $2 \mathrm{mM}$, (B, E and $\mathrm{H}) 5 \mathrm{mM}$, or (C, F and I) $25 \mathrm{mM}$ glucose and a glutamine concentration of 0 mM under normoxic $\left(21 \% \mathrm{O}_{2}\right)$ or hypoxic $\left(0.1 \% \mathrm{O}_{2}\right)$ conditions for $1 \mathrm{~h}$. Cellular lysates were examined by western blot analysis with antibodies for phosphorylated AMPK (p-AMPK), phosphorylated ACC (p-ACC) and actin. p-ACC and p-AMPK intensities were normalized to actin expression (D-I). 2DG, 2-deoxy-d-glucose; ACC, acetyl-CoA carboxylase.

Lactate concentration in SVG cells treated with $2 D G$ and A-769662. To investigate the effects of 2DG and A-769662 on glycolysis under hypoxic and normoxic conditions, the extracellular lactate concentrations in the absence of glutamine were determined. Lactate concentrations in the cell culture medium were measured after 24, 48 and $72 \mathrm{~h}$. The results following treatment with 2DG and A-769662 were compared to those of treatment with the vehicle, DMSO, at the respective time points. A lower lactate concentration in the medium following treatment with 2DG or A-769662 as compared to treatment with the vehicle, DMSO, at the same time point is equivalent to a decrease in lactate production by 2DG or A-769662 treatment, respectively. Treatment of the SVG cells with 2DG reduced lactate production at 2 and $5 \mathrm{mM}$ under both hypoxic and normoxic conditions (Fig. 5). At the supraphysiologically high glucose concentration of $25 \mathrm{mM}$, no effect of treatment with 2DG on lactate production was observed under hypoxic and normoxic conditions. Lactate production was reduced by A-769662 treatment both under normoxic and hypoxic conditions at glucose concentrations of 2,5 and $25 \mathrm{mM}$.

Activation of AMPK via A-769662 increases $O_{2}$ consumption and the ATP concentration. The cellular oxygen consumption was measured to determine the proportion of aerobic metabolism. The results following treatment with 2DG and A-769662 were compared to treatment with the vehicle, DMSO, at the 
$2 \mathrm{mM}$ glucose

A

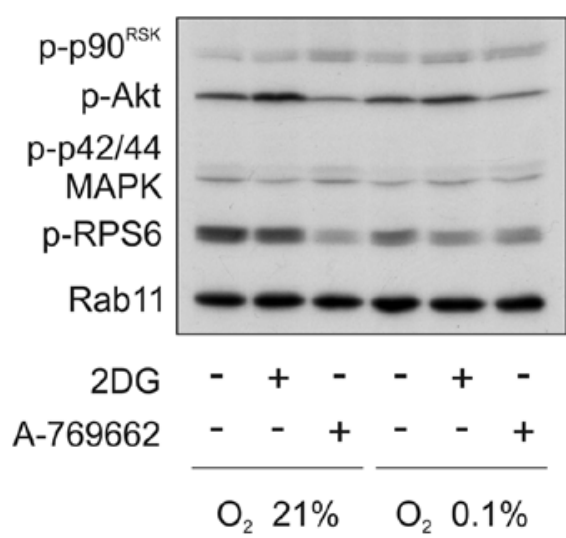

$5 \mathrm{mM}$ glucose

B

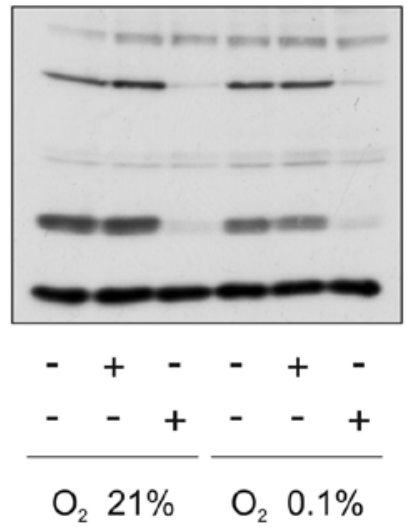

$25 \mathrm{mM}$ glucose

C

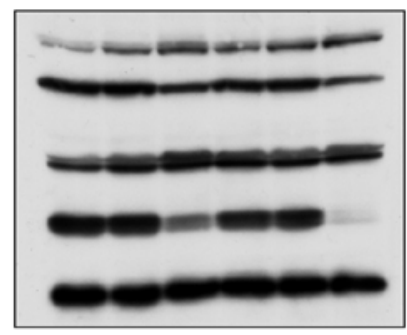

$-+-\quad+-$

$-\quad+--+$

$\mathrm{O}_{2} 21 \% \quad \mathrm{O}_{2} \quad 0.1 \%$
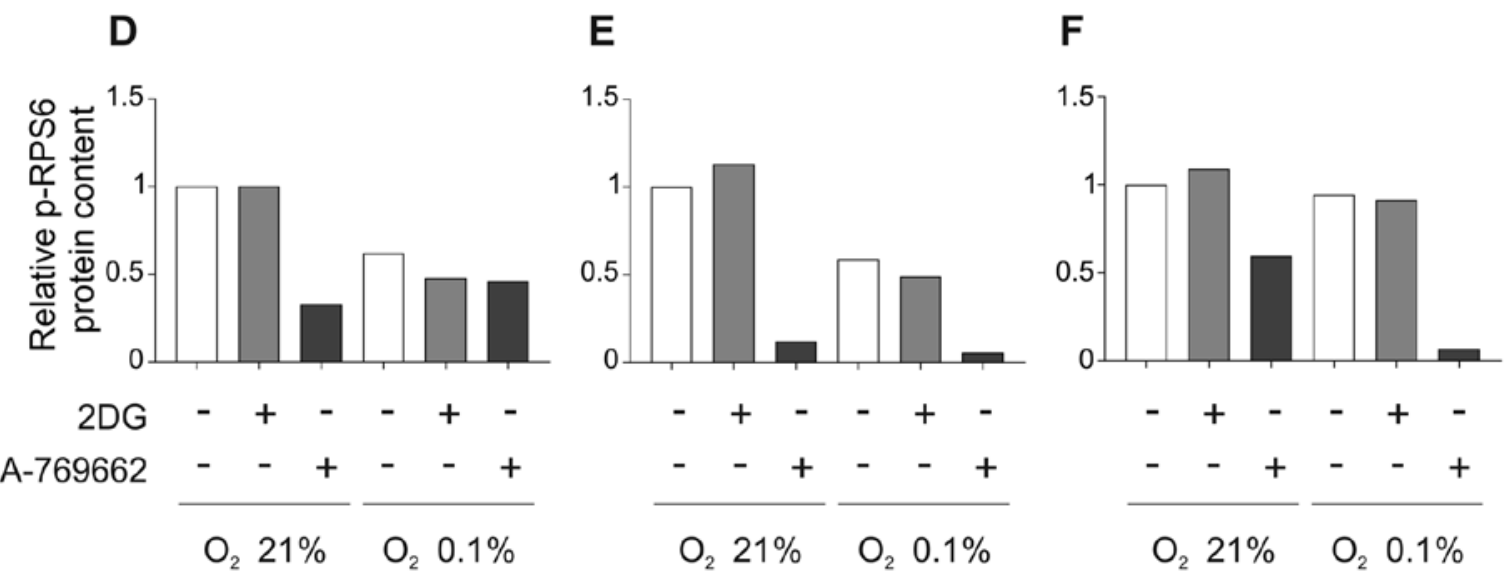

Figure 3. Effect of 2DG and A-769662 on Akt and ribosomal protein S6 (RPS6, mTORC1 downstream target). SVG cells were exposed to serum-free DMEM with glucose concentrations of 2,5 , or $25 \mathrm{mM}$ glucose and $0 \mathrm{mM}$ glutamine under normoxic $\left(21 \% \mathrm{O}_{2}\right)$ or hypoxic $\left(0.1 \% \mathrm{O}_{2}\right)$ conditions for $1 \mathrm{~h}$. Cell lysates were examined by western blot analysis with Pathscan Multiplex Western Cocktail I, containing antibodies against phosphorylated ribosomal protein S6 (p-RPS6), p-Akt and the loading control Rab11 (A-C). p-RPS6 intensities were normalized to Rab11 expression (D-F). 2DG, 2-deoxy-d-glucose; Rab11, Ras-related protein Rab-11; mTORC1, mammalian target of rapamycin complex 1; RPS6, ribosomal protein S6.

respective time points. A lower $\mathrm{O}_{2}$ concentration in the medium following treatment with 2DG or A-769662 as compared to treatment with the vehicle, DMSO, at the same time point is equivalent to an increase in $\mathrm{O}_{2}$ consumption by $2 \mathrm{DG}$ or A-769662 treatment, respectively. The activation of AMPK via A-769662 increased the cellular oxygen consumption of SVG cells at 2, 5 and $25 \mathrm{mM}$ glucose (Fig. 6A, C and D). The inhibition of glycolysis with $2 \mathrm{DG}$ did not increase oxygen consumption significantly. The increased oxygen consumption in conjunction with the decreased glucose consumption and the decreased lactate production of SVG cells treated with A-769662 indicate a switch to more efficient glucose metabolism through oxidative phosphorylation. Glycolysis inhibition with 2DG under normoxic conditions did not alter the ATP concentration (Fig. 6B). However, under hypoxic conditions, treatment with $2 \mathrm{DG}$ reduced the ATP concentration. Direct AMPK activation with A-769662 increased the ATP concentration under both hypoxic and normoxic conditions.

\section{Discussion}

In the present study, it was hypothesized that a preventive induction of energy deprivation-activated signaling pathways via AMPK may protect astrocytes from hypoxia and glucose deprivation. The results revealed that both direct and indirect AMPK activation resulted in a potent protective effect. An overview of the effects of 2DG and A-769662 on SVG cells under oxygen and partial glucose deprivation conditions is illustrated in Fig. 7.

Direct AMPK activation with A-769662, as well as glycolysis inhibition with 2DG protected the SVG cells from hypoxia-induced cell death. Even though this effect was still detectable at high glucose concentrations, it was most potent with low glucose concentrations. This accentuated protective effect of A-769662 at low glucose concentrations indicated a synergistic effect with the intrinsic activation of AMPK induced by the relative lack of glucose.

2DG and A-769662 protected the SVG cells from hypoxia both in the presence and in absence of glutamine. Under hypoxic conditions, ATP cannot be generated from the metabolization of glutamine in the process of glutaminolysis (10). However, under hypoxic conditions, glutamine can still be metabolized through anaplerosis (29). As the addition of glutamine had no effect on the extent of cell death, this demonstrates that anaplerosis did not protect the astrocytes in our paradigm from hypoxia and partial glucose deprivation. 
A

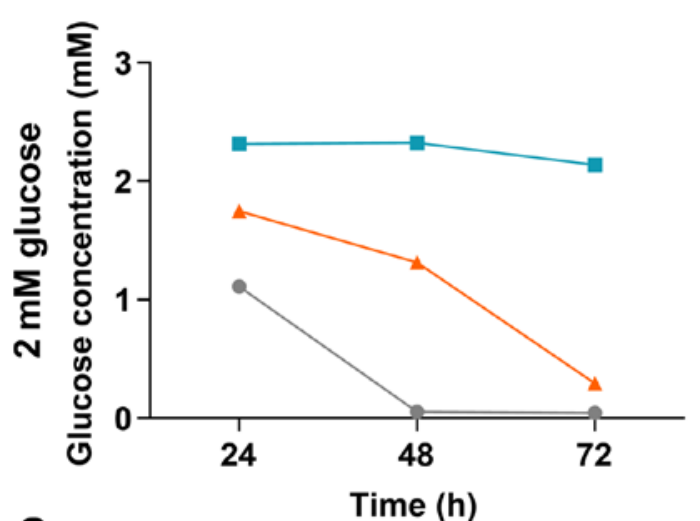

C

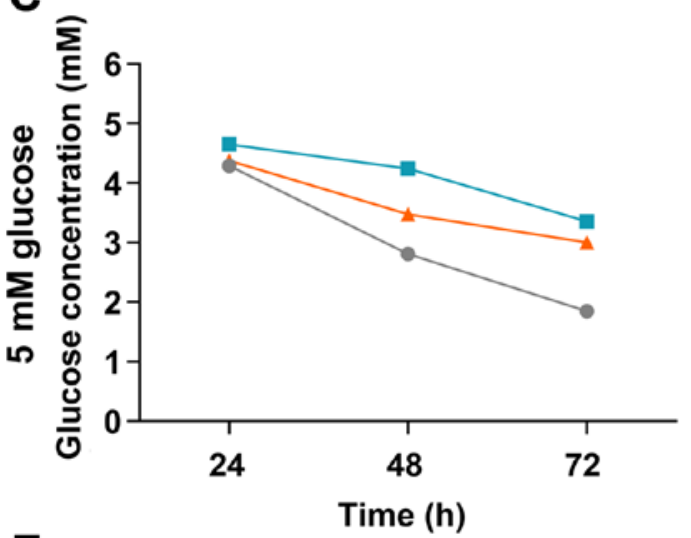

E

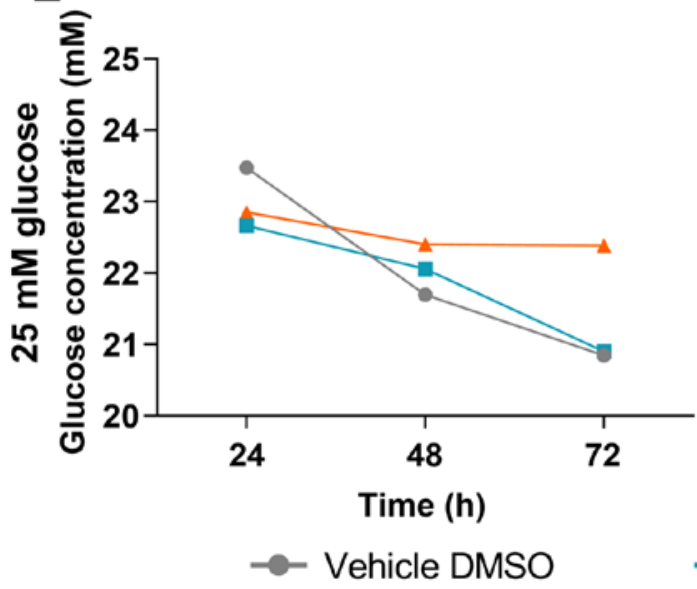

B

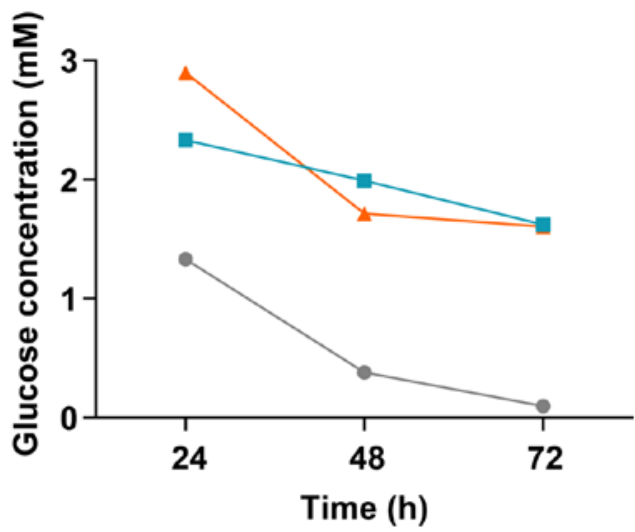

D

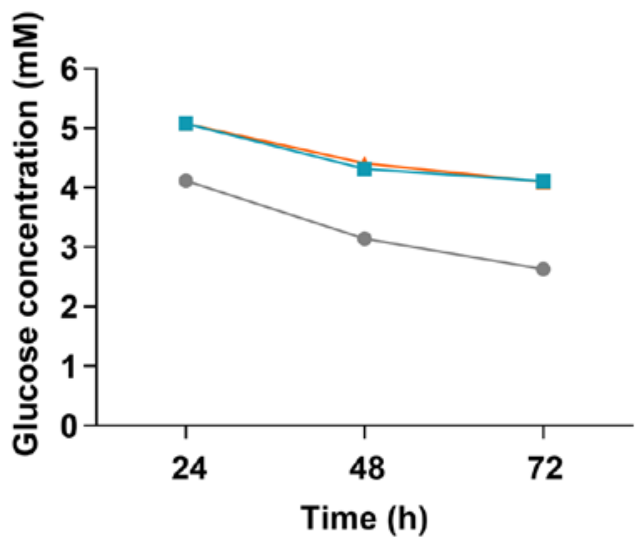

$\mathbf{F}$

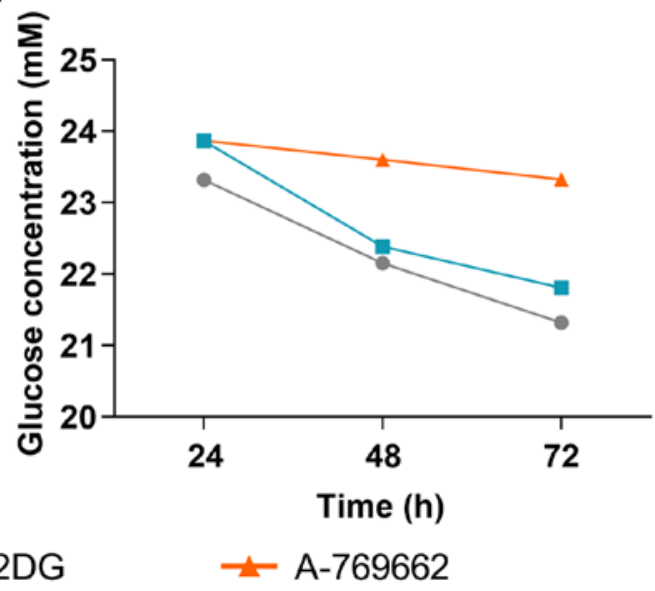

Figure 4. Glucose concentration of SVG cells treated with 2DG and A-769662. At glucose concentrations of 2 and 5 mM, treatment with 2DG and A-769662 resulted in a reduced glucose consumption both under (A and C) hypoxic and (B and D) normoxic conditions. At the high glucose concentration of 25 mM, only A-769662, but not 2DG diminished the glucose consumption under (E) hypoxic and (F) normoxic conditions. Glucose concentrations were measured from pooled supernatant of 5 wells. Please note that glucose concentrations higher than the designated concentrations derive from residual growth medium remaining from the washing step. 2DG, 2-deoxy-d-glucose.

In cortical rat astrocytes, it has been previously demonstrated that AMPK activation induced by metformin exerts a protective effect against oxygen and glucose deprivation (30), and conversely that AMPK inhibition by compound $\mathrm{C}$ increases cell death through a reduced rate of autophagy (31). Furthermore, AMPK activation with AICAR has been shown to protect rodent astrocytes via peroxisome proliferator-activated receptor gamma co-activator $1 \alpha$ (PGC- $1 \alpha)$ activation (32). The present study confirmed the protective effect of AMPK activation with the more specific AMPK activator, A-769662 $(5,33,34)$, in a paradigm of permanent oxygen and glucose deprivation.

Western blot analysis revealed that treatment with A-769662 and 2DG activated AMPK, which resulted in an increased phosphorylation of ACC. The effect of A-769662 was more potent than that of $2 \mathrm{DG}$. This difference was expected due to the direct mechanism of action of A-769662, as compared to the indirect mechanism of 2DG. The inhibition of ACC is known to reduce cellular energy consumption, decreasing the highly energy intensive anabolic process of 

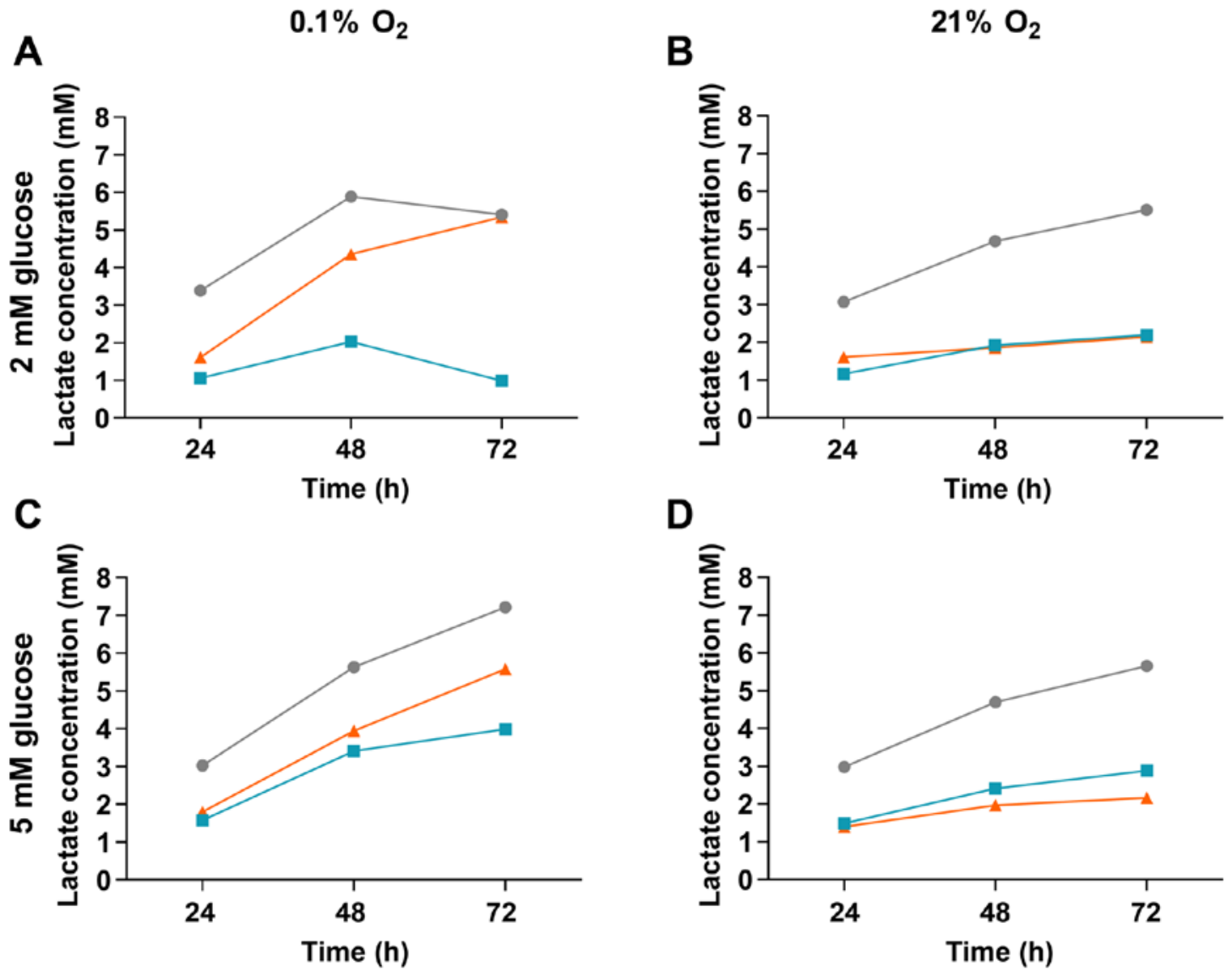

D
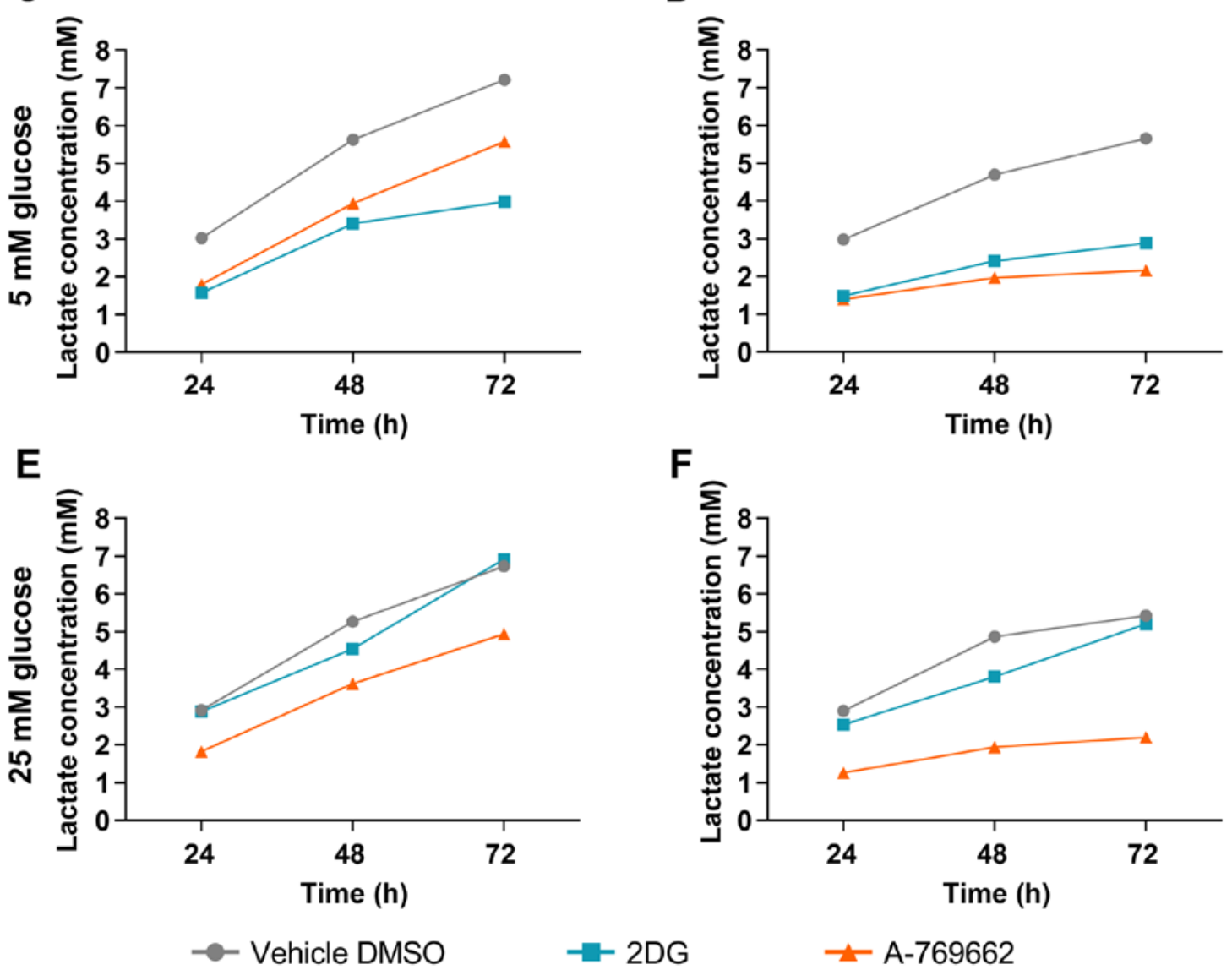

$\mathbf{F}$

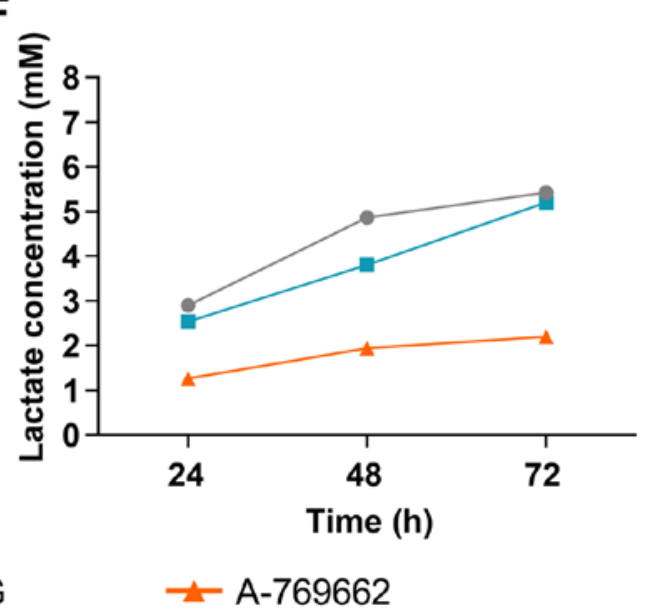

Figure 5. Lactate concentration of SVG cells treated with 2DG and A-769662. At glucose concentrations of 2 and 5 mM, treatment with 2DG and A-769662 reduced lactate production both under (A and C) hypoxic and (B and D) normoxic conditions. At the high glucose concentration of $25 \mathrm{mM}$, only A-769662, but not 2DG diminished lactate production under (E) hypoxic and $(F)$ normoxic conditions. Lactate concentrations were measured from pooled supernatant of 5 wells. 2DG, 2-deoxy-d-glucose.

lipid biosynthesis $(35,36)$. Furthermore, AMPK activation with A-769662 led to an inhibition of Akt and the mTORC1 target protein, RPS6. The inhibition of mTORC1 and its target protein RPS6 have previously been demonstrated to reduce the energy consuming anabolic processes of translation and cellular proliferation $(25,26,28)$.

In contrast to A-769662, 2DG had no marked effect on the phosphorylation of AMPK, ACC, Akt and RPS6 in SVG cells exposed to a supraphysiologically high glucose concentration of $25 \mathrm{mM}$. This discrepancy may be explained by the mechanism of glycolysis inhibition, as 2DG displaces glucose, competitively binds to phosphoglucoisomerase and thus inhibits glycolysis. Due to this competitive mechanism, 2DG does not inhibit glycolysis at high glucose to 2DG ratios (8).

In the present study, direct and indirect AMPK activation led to reduced glucose consumption and lactate production both under normoxic and hypoxic conditions. Furthermore, an increase in oxygen consumption in cells exposed to A-769662 was observed. This increase in oxygen consumption, the decrease in glucose consumption and the decrease in lactate production point to a metabolic switch towards an augmented oxidative phosphorylation. It has already been known that 
A

$2 \mathrm{mM}$ glucose

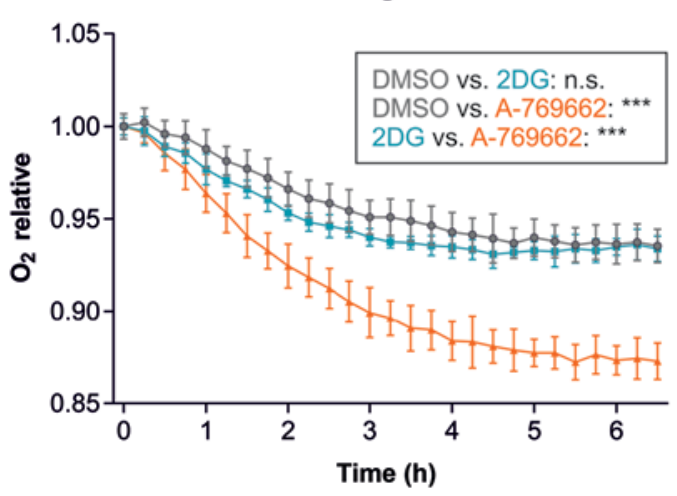

C

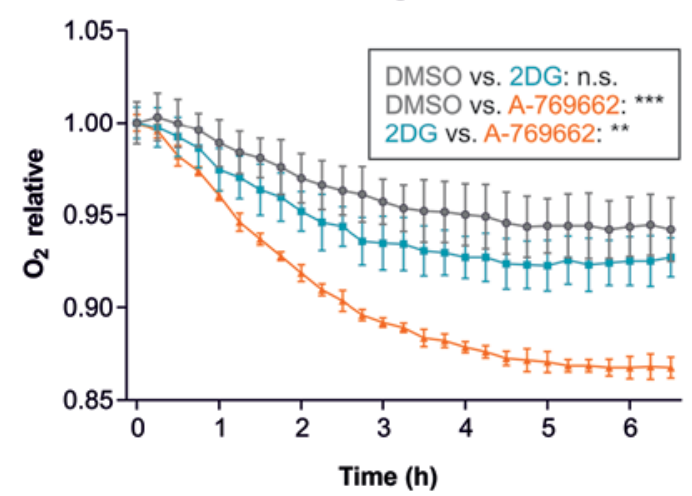

B

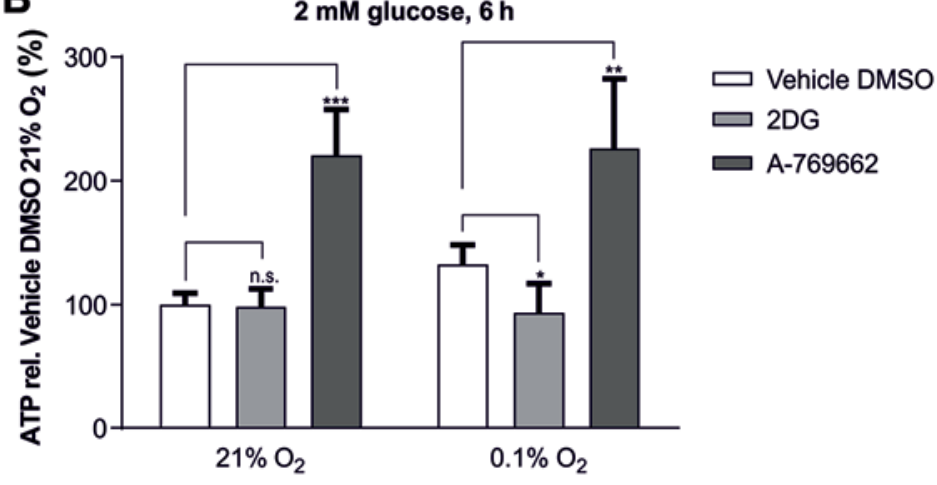

D

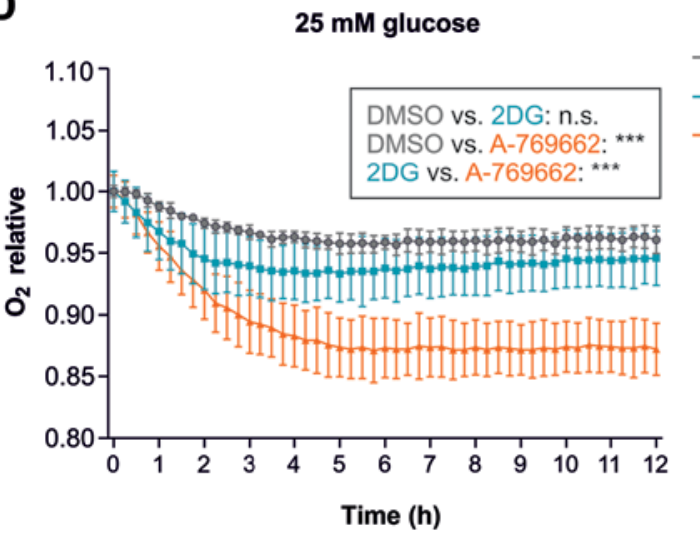

Figure 6. Activation of AMPK via A-769662 increases $\mathrm{O}_{2}$-consumption and ATP concentrations. (A, C and D) Effect of 2 DG and A-769662 on oxygen consumption. SVG cells were exposed to serum-free DMEM with 2, 5 or $25 \mathrm{mM}$ glucose, 0 mM glutamine, vehicle DMSO, $2 \mathrm{DG}$ or A-769662 and overlayed with sterile paraffin oil [ $\mathrm{n}=3$; n.s., not significant $(\mathrm{P} \geq 0.05) ;{ }^{* *} \mathrm{P}<0.01,{ }^{* * *} \mathrm{P}<0.001$, non-linear regression analysis followed by ANOVA with Tukey's multiple comparisons test]. Oxygen was measured with a fluorescence-based assay as the proportion of the initial oxygen concentration under normoxic conditions. (A) Exposure to $2 \mathrm{mM}$ glucose. (C) Exposure to $5 \mathrm{mM}$ glucose. (D) Exposure to $25 \mathrm{mM}$ glucose. (B) ATP concentrations of SVG cells treated with $2 \mathrm{DG}$ or A-769662 normalized to the vehicle DMSO under normoxic conditions. SVG cells were exposed to serum-free DMEM with 2 mM glucose, 0 mM glutamine and the vehicle DMSO, 2DG or A-769662 and incubated for $6 \mathrm{~h}$. ATP concentrations were measured and normalized to the vehicle DMSO. [n=5; n.s., not significant $(\mathrm{P} \geq 0.05) ;{ }^{*} \mathrm{P}<0.05,{ }^{* * *} \mathrm{P}<0.01,{ }^{* * * *} \mathrm{P}<0.001$, ANOVA with Dunnett's multiple comparisons test). 2DG, 2-deoxy-d-glucose.

\section{Untreated}

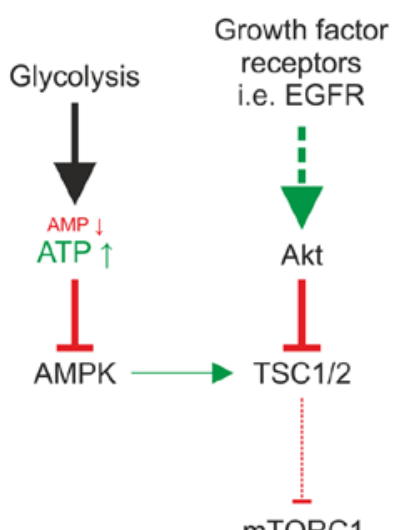

Anabolic metabolism Cellular energy consumption Sensitivity against hypoxia and glucose deprivation
2DG

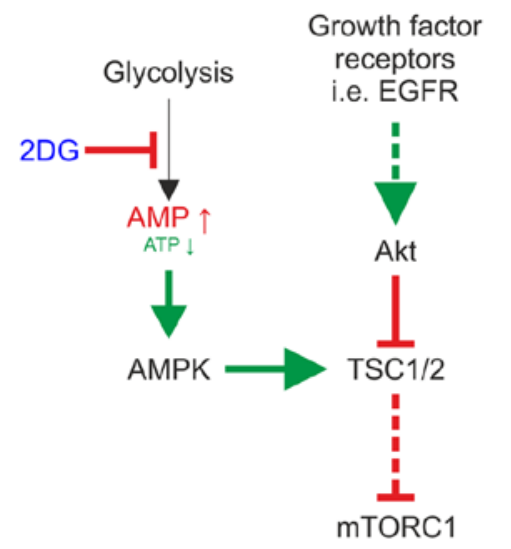

Catabolic metabolism Cellular energy preservation Resistance against hypoxia and glucose deprivation
A-769662

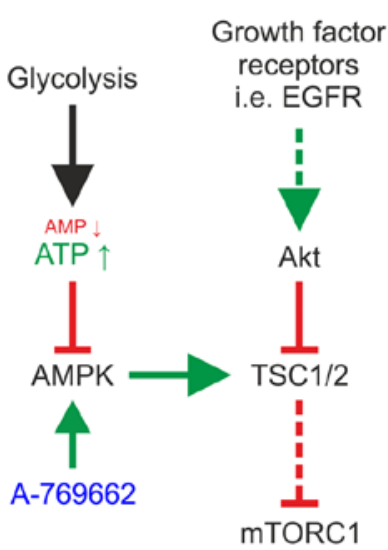

Catabolic metabolism

Cellular energy preservation

Resistance against hypoxia and glucose deprivation

Figure 7. Overview of the suggested effects of 2DG and A-769662 on SVG cells in the paradigm of oxygen and partial glucose deprivation in this study. Direct, as well as indirect AMPK activation reduces anabolic metabolism and cellular energy consumption. This results in an increased resistance against hypoxia and partial glucose deprivation. ATP, adenosine triphosphate; AMPK, 5'adenosine monophosphate-activated protein kinase; mTORC1, mammalian target of rapamycin complex 1; TSC1, tuberous sclerosis 1; 2DG, 2-deoxy-d-glucose; EGFR, epidermal growth factor receptor. 
the A-769662 treatment of astrocytes increases extracellular ATP levels (37). The present study demonstrated that direct AMPK activation with A-769662 increased the intracellular ATP concentrations as well, potentially due to a reduced rate of ATP consumption in anabolic processes. In contrast to glycolysis inhibition with 2DG, direct AMPK activation with A-769662 is not expected to restrict ATP production. By contrast, glycolysis inhibition with 2DG reduced cellular ATP concentrations under hypoxic conditions when SVG cells fully depend on anaerobic glycolysis for ATP production. Nevertheless, even though ATP levels were reduced by 2DG treatment under hypoxic conditions, the protective effect was still present. It was thus speculated that the negative effect of indirect AMPK activation by 2DG on ATP consumption was sufficiently potent to balance the lower ATP levels due to relatively higher glucose levels for a longer period of time and to thus delay the subsequently resulting disequilibrium of ATP production and consumption finally leading to cell death.

Under the paradigm of sublethal oxygen/glucose deprivation with subsequent reoxygenation, a reactive induction of astrocytic proliferation after reoxygenation is observed $(38,39)$. The experimental conditions of this study differed in that the glucose/oxygen deprivation applied was permanent and no reoxygenation was performed to specifically measure the amount of cell death occurring under hypoxia and glucose deprivation. This paradigm of hypoxia- and glucose deprivation-induced cell death was intentionally selected in order to focus on the extent of cell death occurring under these static adverse conditions. This is indeed a simplification of the complex processes occurring during ischemic brain infarction. However, the penumbra of an ischemic lesion is characterized by a reduced perfusion as observed in perfusion-weighted magnetic resonance imaging. Even though this residual perfusion is not sufficient to preserve the tissue affected from ischemic cell death, it may be sufficient to allow for pharmacologic interventions $(40,41)$. Therefore, the preventive induction of energy deprivation-activated signaling pathways via AMPK activation is a promising research approach with which to prolong the time window during ischemic stroke.

The limitations of the present study include the use of the immortalized astrocytic cell line, SVG. While of human origin, it should be noted that SVG is a SV40-transformed cell line and therefore may exhibit metabolic differences as compared to normal human astrocytes.

In conclusion, the findings of the present study demonstrate that direct, as well as indirect AMPK activation protects astrocytic cells from hypoxic cell death. AMPK activation may thus prove to be an indirect neuroprotective strategy for the management of cerebral ischemia via the preservation of function and integrity of astrocytes.

\section{Acknowledgements}

Not applicable.

\section{Funding}

The present study was supported by the Dr. Senckenberg Institute of Neurooncology which is supported by the Senckenberg foundation.

\section{Availability of data and materials}

All data generated or analyzed during this study are included in this published article or are available from the corresponding author on reasonable request.

\section{Authors' contributions}

LB, MWR, JPS and MCB were involved in the conceptualization of the study. LB, MIS, ALL, MJ, IB, ACMS, ICM, SMH, AD, NIL, MV, MWR, JPS and MCB were involved in the study methodology. LB was involved in the investigative aspect of the study, and in the writing and preparation of the original draft of the manuscript. LB, MIS, ALL, MJ, IB, ACMS, ICM, SMH, AD, NIL, MV, MWR, JPS and MCB were involved in the writing, reviewing and editing of the manuscript. MWR, JPS and MCB were involved in study supervision. All authors read and approved the final manuscript.

\section{Ethics approval and consent to participate}

Not applicable.

\section{Patient consent for publication}

Not applicable.

\section{Competing interests}

The authors declare that they have no competing interests.

\section{References}

1. Hardie DG, Ross FA and Hawley SA: AMPK: A nutrient and energy sensor that maintains energy homeostasis. Nat Rev Mol Cell Biol 13: 251-262, 2012.

2. Mitsudomi T and Yatabe Y: Epidermal growth factor receptor in relation to tumor development: EGFR gene and cancer. FEBS J 277: 301-308, 2010.

3. Wullschleger $\mathrm{S}$, Loewith $\mathrm{R}$ and Hall MN: TOR signaling in growth and metabolism. Cell 124: 471-484, 2006.

4. Hardie DG and Pan DA: Regulation of fatty acid synthesis and oxidation by the AMP-activated protein kinase. Biochem Soc Trans 30: 1064-1070, 2002.

5. Goransson O, McBride A, Hawley SA, Ross FA, Shpiro N, Foretz M, Viollet B, Hardie DG and Sakamoto K: Mechanism of action of A-769662, a valuable tool for activation of AMP-activated protein kinase. J Biol Chem 282: 32549-32560, 2007.

6. Hartel I, Ronellenfitsch M, Wanka C, Wolking S, Steinbach JP and Rieger J: Activation of AMP-activated kinase modulates sensitivity of glioma cells against epidermal growth factor receptor inhibition. Int J Oncol 49: 173-180, 2016.

7. Strickland $M$ and Stoll EA: Metabolic reprogramming in glioma. Front Cell Dev Biol 5: 43, 2017.

8. Woodward GE and Hudson MT: The effect of 2-desoxy-D-glucose on glycolysis and respiration of tumor and normal tissues. Cancer Res 14: 599-605, 1954.

9. Wick AN, Drury DR, Nakada HI and Wolfe JB: Localization of the primary metabolic block produced by 2-deoxyglucose. J Biol Chem 224: 963-969, 1957.

10. Yang C, Ko B, Hensley CT, Jiang L, Wasti AT, Kim J, Sudderth J, Calvaruso MA, Lumata L, Mitsche M, et al: Glutamine oxidation maintains the TCA cycle and cell survival during impaired mitochondrial pyruvate transport. Mol Cell 56: 414-424, 2014.

11. Sellers K, Fox MP, Bousamra M II, Slone SP, Higashi RM, Miller DM, Wang Y, Yan J, Yuneva MO, Deshpande R, et al: Pyruvate carboxylase is critical for non-small-cell lung cancer proliferation. J Clin Invest 125: 687-698, 2015. 
12. Csibi A, Fendt SM, Li C, Poulogiannis G, Choo AY, Chapski DJ, Jeong SM, Dempsey JM, Parkhitko A, Morrison T, et al: The mTORC1 pathway stimulates glutamine metabolism and cell proliferation by repressing SIRT4. Cell 153: 840-854, 2013.

13. Becerra-Calixto A and Cardona-Gomez GP: The role of astrocytes in neuroprotection after brain stroke: Potential in cell therapy. Front Mol Neurosci 10: 88, 2017.

14. Heiss WD: The concept of the penumbra: Can it be translated to stroke management? Int J Stroke 5: 290-295, 2010.

15. Candelario-Jalil E: Injury and repair mechanisms in ischemic stroke: Considerations for the development of novel neurotherapeutics. Curr Opin Investig Drugs 10: 644-654, 2009.

16. Khaladj N, Peterss S, Oetjen P, von Wasielewski R, Hauschild G, Karck M, Haverich A and Hagl C: Hypothermic circulatory arrest with moderate, deep or profound hypothermic selective antegrade cerebral perfusion: Which temperature provides best brain protection? Eur J Cardiothorac Surg 30: 492-498, 2006.

17. Pacini D, Leone A, Di Marco L, Marsilli D, Sobaih F, Turci S, Masieri V and Di Bartolomeo R: Antegrade selective cerebral perfusion in thoracic aorta surgery: Safety of moderate hypothermia. Eur J Cardiothorac Surg 31: 618-622, 2007.

18. Abbott NJ, Ronnback L and Hansson E: Astrocyte-endothelial interactions at the blood-brain barrier. Nat Rev Neurosci 7: 41-53, 2006

19. Newman EA: Glial cell regulation of neuronal activity and blood flow in the retina by release of gliotransmitters. Philos Trans R Soc Lond B Biol Sci 370: 2015.

20. Kitchen P, Day RE, Taylor LH, Salman MM, Bill RM, Conner MT and Conner AC: Identification and molecular mechanisms of the rapid tonicity-induced relocalization of the aquaporin 4 channel J Biol Chem 290: 16873-16881, 2015.

21. Kaczor P, Rakus D and Mozrzymas JW: Neuron-astrocyte interaction enhance GABAergic synaptic transmission in a manner dependent on key metabolic enzymes. Front Cell Neurosci 9: $120,2015$.

22. Xie Z, Ding SQ and Shen YF: Silibinin activates AMP-activated protein kinase to protect neuronal cells from oxygen and glucose deprivation-re-oxygenation. Biochem Biophys Res Commun 454: 313-319, 2014.

23. Major EO, Miller AE, Mourrain P, Traub RG, de Widt E and Sever J: Establishment of a line of human fetal glial cells that supports JC virus multiplication. Proc Natl Acad Sci USA 82: $1257-1261,1985$.

24. Bachis A, Major EO and Mocchetti I: Brain-derived neurotrophic factor inhibits human immunodeficiency virus-1/gp120-mediated cerebellar granule cell death by preventing gp120 internalization. J Neurosci 23: 5715-5722, 2003.

25. Steinbach JP, Wolburg H, Klumpp A, Probst H and Weller M: Hypoxia-induced cell death in human malignant glioma cells: Energy deprivation promotes decoupling of mitochondrial cytochrome c release from caspase processing and necrotic cell death. Cell Death Differ 10: 823-832, 2003.

26. Steinbach JP, Klumpp A, Wolburg H and Weller M: Inhibition of epidermal growth factor receptor signaling protects human malignant glioma cells from hypoxia-induced cell death. Cancer Res 64: 1575-1578, 2004.

27. Thiepold AL, Lorenz NI, Foltyn M, Engel AL, Divé I, Urban H, Heller S, Bruns I, Hofmann U, Dröse S, et al: Mammalian target of rapamycin complex 1 activation sensitizes human glioma cells to hypoxia-induced cell death. Brain 140: 2623-2638, 2017.

28. Ronellenfitsch MW, Brucker DP, Burger MC, Wolking S Tritschler F, Rieger J, Wick W, Weller M and Steinbach JP: Antagonism of the mammalian target of rapamycin selectively mediates metabolic effects of epidermal growth factor receptor inhibition and protects human malignant glioma cells from hypoxia-induced cell death. Brain 132: 1509-1522, 2009.
29. Wise DR, Ward PS, Shay JE, Cross JR, Gruber JJ, Sachdeva UM, Platt JM, DeMatteo RG, Simon MC and Thompson CB: Hypoxia promotes isocitrate dehydrogenase-dependent carboxylation of $\alpha$-ketoglutarate to citrate to support cell growth and viability. Proc Natl Acad Sci USA 108: 19611-19616, 2011

30. Gabryel B, Kost A, Kasprowska D, Liber S, Machnik G, Wiaderkiewicz R and Łabuzek K: AMP-activated protein kinase is involved in induction of protective autophagy in astrocytes exposed to oxygen-glucose deprivation. Cell Biol Int 38: 1086-1097, 2014

31. Gabryel B and Liber S: Metformin limits apoptosis in primary rat cortical astrocytes subjected to oxygen and glucose deprivation. Folia Neuropathol 56: 328-336, 2018.

32. Guo X, Jiang Q, Tuccitto A, Chan D, Alqawlaq S, Won GJ and Sivak JM: The AMPK-PGC-1 $\alpha$ signaling axis regulates the astrocyte glutathione system to protect against oxidative and metabolic injury. Neurobiol Dis 113: 59-69, 2018.

33. Viollet B, Guigas B, Leclerc J, Hébrard S, Lantier L, Mounier R, Andreelli $\mathrm{F}$ and Foretz M: AMP-activated protein kinase in the regulation of hepatic energy metabolism: From physiology to therapeutic perspectives. Acta Physiol (Oxf) 196: 81-98, 2009.

34. Dasgupta B and Seibel W: Compound c/dorsomorphin: Its use and misuse as an AMPK inhibitor. Methods Mol Biol 1732: 195-202, 2018.

35. Shin SY, Kim TH, Wu H, Choi YH and Kim SG: SIRT1 activation by methylene blue, a repurposed drug, leads to AMPK-mediated inhibition of steatosis and steatohepatitis. Eur J Pharmacol 727: $115-124,2014$

36. Wu L, Zhang L, Li B, Jiang H, Duan Y, Xie Z, Shuai L, Li J and $\mathrm{Li}$ J: AMP-activated protein kinase (AMPK) regulates energy metabolism through modulating thermogenesis in adipose tissue. Front Physiol 9: 122, 2018.

37. Vlachaki Walker JM, Robb JL, Cruz AM, Malhi A, Weightman Potter PG, Ashford MLJ, McCrimmon RJ, Ellacott KLJ and Beall C: AMP-activated protein kinase (AMPK) activator A-769662 increases intracellular calcium and ATP release from astrocytes in an AMPK-independent manner. Diabetes Obes Metab 19: 997-1005, 2017.

38. Zhao X, Zhou KS, Li ZH, Nan W, Wang J, Xia YY and Zhang HH: Knockdown of Ski decreased the reactive astrocytes proliferation in vitro induced by oxygen-glucose deprivation/reoxygenation. J Cell Biochem 119: 4548-4558, 2018.

39. He M, Shi X, Yang M, Yang T, Li T and Chen J: Mesenchymal stem cells-derived IL- 6 activates AMPK/mTOR signaling to inhibit the proliferation of reactive astrocytes induced by hypoxic-ischemic brain damage. Exp Neurol 311: 15-32, 2019.

40. Lin L, Bivard A and Parsons MW: Perfusion patterns of ischemic stroke on computed tomography perfusion. J Stroke 15: 164-173, 2013.

41. Lee DH, Kang DW, Ahn JS, Choi CG, Kim SJ and Suh DC: Imaging of the ischemic penumbra in acute stroke. Korean J Radiol 6: 64-74, 2005 .

This work is licensed under a Creative Commons Attribution-NonCommercial-NoDerivatives 4.0 International (CC BY-NC-ND 4.0) License. 